Article

\title{
The High-Pressure Structural Evolution of Olivine along the Forsterite-Fayalite Join
}

\author{
Martha G. Pamato ${ }^{1, *(\mathbb{D}}$, Fabrizio Nestola ${ }^{1} \mathbb{D}$, Davide Novella ${ }^{2}$, Joseph R. Smyth ${ }^{3}$, \\ Daria Pasqual $^{1}$, G. Diego Gatta ${ }^{4}\left(\mathbb{0}\right.$, Matteo Alvaro $^{2}$ and Luciano Secco ${ }^{1}$ \\ 1 Department of Geosciences, University of Padova, Via G. Gradenigo 6, 35131 Padova, Italy; \\ fabrizio.nestola@unipd.it (F.N.); daria.pasqual@unipd.it (D.P.); luciano.secco@unipd.it (L.S.) \\ 2 Department of Earth and Environmental Sciences, University of Pavia, Via A. Ferrata 1, 27100 Pavia, Italy; \\ davide.novella@unipv.it (D.N.); matteo.alvaro@unipv.it (M.A.) \\ 3 Department of Geological Sciences, University of Colorado, 2200 Colorado Ave, Boulder, CO 80309, USA; \\ smyth@colorado.edu \\ 4 Department of Earth Sciences, University of Milan, Via Botticelli 23, 20133 Milan, Italy; diego.gatta@unimi.it \\ * Correspondence: martha.pamato@unipd.it
}

Received: 7 November 2019; Accepted: 11 December 2019; Published: 14 December 2019

\begin{abstract}
Structural refinements from single-crystal X-ray diffraction data are reported for olivine with a composition of $\mathrm{Fo}_{100}$ (forsterite $\mathrm{Mg}_{2} \mathrm{SiO}_{4}$, synthetic), $\mathrm{Fo}_{80}$ and $\mathrm{Fo}_{62}\left(\sim \mathrm{Mg}_{1.6} \mathrm{Fe}_{0.4} \mathrm{SiO}_{4}\right.$ and $\sim \mathrm{Mg}_{1.24} \mathrm{Fe}_{0.76} \mathrm{SiO}_{4}$, both natural) at room temperature and high pressure to $\sim 8 \mathrm{GPa}$. The new results, along with data from the literature on $\mathrm{Fo}_{0}$ (fayalite $\mathrm{Fe}_{2} \mathrm{SiO}_{4}$ ), were used to investigate the previously reported structural mechanisms which caused small variations of olivine bulk modulus with increasing Fe content. For all the investigated compositions, the M2 crystallographic site, with its bonding configuration and its larger polyhedral volume, was observed to control the compression mechanisms in olivine. From $\mathrm{Fo}_{100}$ to $\mathrm{Fo}_{0}$, the compression rates for $\mathrm{M} 2-\mathrm{O}$ and $\mathrm{M} 1-\mathrm{O}$ bond lengths were observed to control the relative polyhedral volumes, resulting in a less-compressible $\mathrm{M}_{1} \mathrm{O}_{6}$ polyhedral volume, likely causing the slight increase in bulk modulus with increasing Fe content.
\end{abstract}

Keywords: olivine; forsterite; fayalite; crystal structure; high pressure; X-ray diffraction

\section{Introduction}

In order to understand the formation and evolution of the solid Earth, a precise knowledge of the elastic properties (e.g., bulk and shear modulus) of minerals present in the Earth's interior at high pressures and high temperatures is necessary. These data are the basis for interpreting seismological profiles needed to determine the structure and composition of the Earth's inaccessible interior (e.g., [1]). Olivine is the most abundant mineral in the upper mantle (51-60\%; [2]) extending from the base of the crust to approximately $410 \mathrm{~km}$. In natural systems, olivine forms a solid solution between two $\mathrm{Mg}$ and $\mathrm{Fe}$ end members, namely $\mathrm{Mg}_{2} \mathrm{SiO}_{4}$ forsterite ( $\mathrm{Fo}$ ) and $\mathrm{Fe}_{2} \mathrm{SiO}_{4}$ fayalite (Fa). At depths greater than $410 \mathrm{~km}$, olivine is no longer stable and transforms to its high-pressure polymorph wadsleyite ( $\beta$-olivine). This transformation is the cause of the $410 \mathrm{~km}$ seismic discontinuity that separates the upper mantle from the deeper transition zone (e.g., [3]). The exact pressure of this transition is a function of the Fe content of the system at a particular temperature (see [4] and references therein). Therefore, to understand the structure and composition of the mantle, and consequently global dynamics, accurate knowledge of the evolution of the elastic properties of olivine as a function of pressure and chemical composition is required.

The crystal structure of olivine (Pbnm space group) can be described as an expanded and distorted hexagonally close-packed (hcp) array of oxygen anions stacked along the $a$ axis (e.g., [5,6]). Si cations 
are located at tetrahedral sites, whereas $\mathrm{Mg}$ and Fe are disordered in two distinct octahedral sites, with the M1 polyhedron being smaller and more distorted than the M2 polyhedron (Figure 1).

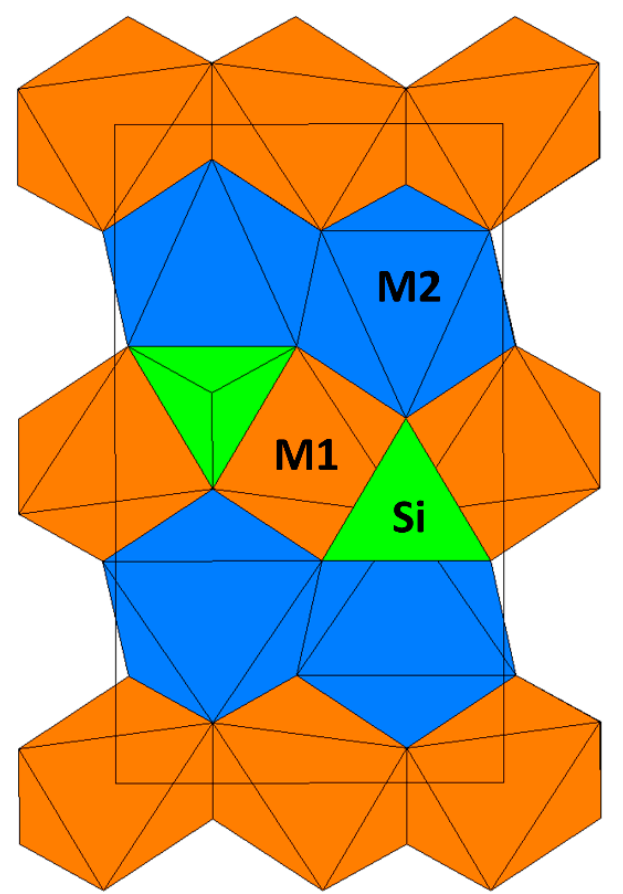

Figure 1. Crystal structure of olivine plotted down the $a$ axis. The $b$ axis is plotted vertically (positive direction upwards), whereas the $c$ axis is plotted horizontally (positive direction towards left). Atomic sites M2, M1, and Si are highlighted. The black rectangle represents the unit cell.

Many studies have been conducted in the past four decades in order to determine the elastic properties of olivine (e.g., the bulk modulus) as a function of pressure and composition (see [7-22]). However, the results of these studies have shown significant scattering. Nestola et al. [18] conducted a systematic study of the elastic properties of the Mg-rich side of the forsterite-fayalite join, which is relevant for mantle compositions. Importantly, this study illustrated that the isothermal bulk modulus $\left(K_{\mathrm{T} 0}\right)$ and its first pressure derivative $\left(K^{\prime}\right)$ do not vary significantly between $\mathrm{Fo}_{92}$ to $\mathrm{Fo}_{62}$, thus a single equation of state was determined for the entire compositional range with $K_{\mathrm{T} 0}=124.7(9)$ GPa and $K^{\prime}=5.3(3)$. More recently, Angel et al. [21] reviewed all available single-crystal data from the literature and constrained the elastic properties and pressure-volume-temperature equation of state (EoS) of mantle-composition olivine. For an olivine with Fo92-90 composition, these authors provided a $K_{\mathrm{T} 0}=126.3(2) \mathrm{GPa}$ and $K^{\prime}=4.54(6)$. On the Fe-rich side of the forsterite-fayalite join, Hazen [7] determined a $K_{\mathrm{T} 0}$ of $113 \mathrm{GPa}\left(K^{\prime}\right.$ fixed to 4$)$ for a synthetic fayalite. More recently, Speziale et al. [16] used Brillouin scattering to determine the single-crystal elastic constants of a Fe-rich olivine $\left(\mathrm{Fe}_{0.94} \mathrm{Mn}_{0.06}\right)_{2} \mathrm{SiO}_{4}$ and provided an adiabatic bulk modulus $\left(K_{\mathrm{s} 0}\right)$ of $134 \mathrm{GPa}$, which corresponds to a $K_{\mathrm{T} 0}$ of about $135 \mathrm{GPa}$. The bulk modulus of Speziale et al. [16] is considered to be more accurate than the value obtained by Hazen [7], given the pioneering technology used more than 40 years ago in the latter study. In fact, a very recent work using synchrotron light in a multi-anvil apparatus [22] reported bulk moduli of 131.4 GPa for Fo55, 132.1 for Fo $36,136.3$ for Fo 18 , and 134.8 for $\mathrm{Fo}_{0}$, in agreement with Speziale et al. [16]. These data confirmed that increasing the fraction of Fe in olivine stiffens its structure and increases the bulk modulus, possibly not following a linear trend. However, the reasons for this trend still require further understanding.

Crystallographic studies can provide insights into the nature of interatomic forces and compression mechanisms that control mineral elasticity. This is especially true with regards to Mg-rich olivine that, as mentioned above, displays almost no bulk modulus variation along a large compositional variability 
from $\mathrm{Fo}_{100}$ to $\mathrm{Fo}_{62}$ [18]. Therefore, it is crucial to understand the factors controlling its compression mechanisms. Finkelstein et al. [19] and Zhang et al. [20] recently investigated the crystal structure evolution of olivine end members Fo and Fa, respectively. However, a systematic study describing the structural evolution of olivine as a function of pressure and chemical composition is still lacking.

This study reports structural refinements from single-crystal X-ray diffraction data obtained on olivines with composition $\mathrm{Fo}_{100}$ (synthetic), $\mathrm{Fo}_{80}$, and $\mathrm{Fo}_{62}$ (natural) collected at room temperature and high pressure up to approximately $8 \mathrm{GPa}$. The new results, along with data from the literature on $\mathrm{Fo}_{0}$, are used to discuss and clarify the effect of $\mathrm{Mg} / \mathrm{Fe}$ substitution on the structural deformation mechanisms occurring along the forsterite-fayalite join, relevant to upper-mantle compositions. In particular, this study focused on which structural mechanisms, at the atomic scale, can cause the very small variations of bulk modulus and its first pressure derivative that have been previously reported [18].

\section{Materials and Methods}

Three olivine single crystals $\left(\mathrm{Fo}_{100}, \mathrm{Fo}_{80}\right.$, and $\left.\mathrm{F}_{62}\right)$ were investigated by single-crystal $\mathrm{X}$-ray diffraction. Twin- and inclusion-free crystals for each composition, with typical dimensions $<100 \mu \mathrm{m}$, were selected based on their sharp diffraction peaks. The $\mathrm{Fo}_{100}$ sample is a pure forsterite crystal that was synthesized in an experiment at room pressure and $1600{ }^{\circ} \mathrm{C}$ described in Smyth et al. [23]. The Fo and $\mathrm{Fo}_{62}$ specimens are natural crystals from the volcanic rocks of the Boseti Complex, Main Ethiopian Rift [24]. In detail, the two Fe-bearing olivines are samples from transitional alkaline basalts (BO 321) and strongly porphyritic basalts (BO 335), respectively (see Princivalle and Secco [24]). Single-crystal $X$-ray diffraction results and electron microprobe analyses were reported by Princivalle and Secco [24], and in the more recent study of Nestola et al. [18].

The cation distributions in terms of $\mathrm{Mg}$ and Fe reported by [24] for $\mathrm{Fo}_{80}$ and $\mathrm{Fo}_{62}$ are the following:

$\mathrm{Fo}_{80}$ (sample BO 321): M1 (Mg0.80, Fe0.20); M2 (Mg0.81, Fe0.19);

$\mathrm{Fo}_{62}$ (sample BO 335): M1 (Mg0.59, Fe0.40); M2 (Mg0.61, Fe0.38).

Olivine single crystals were loaded in an ETH-type diamond-anvil cell (DAC) to determine the evolution of their crystal structure at pressures up to $\sim 8 \mathrm{GPa}$. High-pressure experiments were conducted separately for each composition, following the procedure described in Nestola et al. [18]. In particular, the samples were loaded on pre-indented T301 steel foil gaskets with holes of approximately $250 \mu \mathrm{m}$. A methanol:ethanol:water solution (in 16:3:1 ratio) was employed as the pressure-transmitting medium, which provides hydrostatic conditions up to $\approx 9.5 \mathrm{GPa}[25,26]$, covering the pressure range investigated in this study. Pressures were determined by measuring the fluorescence of ruby chips [27], which were loaded in the sample chamber along with the olivine crystal.

Unit-cell parameters and intensity data (for structural refinements) were measured at nine different pressures up to approximately $8 \mathrm{GPa}$ for forsterite $\left(\mathrm{Fo}_{100}\right)$, and at seven different pressures up to $\sim 7.7$ and $8.3 \mathrm{GPa}$ for $\mathrm{Fo}_{80}$ and $\mathrm{Fo}_{62}$, respectively. The measurements were carried out using a STOE STADI4 four-circle diffractometer (monochromatized Mo K $\alpha$ radiation) (STOE \& Cie GmbH, Darmstadt, Germany) equipped with an Oxford Diffraction CCD detector, with a sample-detector distance of $60 \mathrm{~mm}$. Diffraction data were collected up to $2 \theta \max =60^{\circ}$ using an exposure time of $60 \mathrm{~s} /$ frame and an $\omega$-scan of $0.2^{\circ}$ in order to obtain coverage of the full reciprocal sphere and the highest possible precision in the unit-cell parameters determination. The Crysalis Red program (Oxford Diffraction) was used to integrate the intensity data, applying the Lorentz-polarization correction. The absorption correction for the crystal, DAC, and gasket shadowing was performed using Absorb 6.0 [28] and X-Shape [29]. Weighted structural isotropic refinements were performed using the SHELXL-97 software [30], starting from the atomic coordinates of Fujino et al. [31] in the Pbnm space group. No violation of the reflection conditions for this space group were observed to the maximum pressure reached for all the samples. 


\section{Results}

Unit-cell parameters and structure refinement results are reported in Table 1, whereas bond lengths and polyhedral data are reported in Table S1 in the Supplementary Material. The atomic coordinates of all samples at all pressures are provided as CIF files in the Supplementary Material.

Table 1. Unit-cell parameters and structure refinement results for the olivine crystals studied here.

\begin{tabular}{|c|c|c|c|c|c|c|c|c|c|}
\hline \multicolumn{10}{|c|}{$\mathrm{Fo}_{100} \mathrm{Fa}_{0}$} \\
\hline$P(\mathrm{GPa})$ & 0 & $1.22(5)$ & $2.04(5)$ & $2.67(5)$ & $3.28(5)$ & $4.82(5)$ & $6.29(5)$ & $7.23(5)$ & $7.98(5)$ \\
\hline$a(\AA)$ & $4.758(4)$ & $4.750(3)$ & $4.741(3)$ & $4.734(4)$ & $4.734(2)$ & $4.725(4)$ & $4.714(3)$ & $4.704(2)$ & $4.700(3)$ \\
\hline$b(\AA)$ & $10.190(7)$ & $10.162(6)$ & $10.148(7)$ & $10.112(7)$ & $10.112(5)$ & $10.054(7)$ & $10.017(7)$ & $9.993(5)$ & $9.959(5)$ \\
\hline$c(\AA)$ & $5.982(6)$ & $5.962(4)$ & $5.946(4)$ & $5.950(4)$ & $5.924(3)$ & $5.909(6)$ & $5.889(5)$ & $5.872(4)$ & $5.866(4)$ \\
\hline$V\left(\AA^{3}\right)$ & $290.0(4)$ & $287.8(3)$ & $286.1(3)$ & $284.8(4)$ & $283.6(2)$ & $280.7(4)$ & $278.1(4)$ & $276.0(3)$ & $274.6(3)$ \\
\hline S.G. & Pbnm & Pbnm & Pbnm & Pbnm & Pbnm & Pbnm & Pbnm & Pbnm & Pbnm \\
\hline Radiation & Mo $K \alpha$ & $\operatorname{Mo} K \alpha$ & $\operatorname{Mo} K \alpha$ & 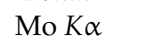 & Mo $K \alpha$ & Mo $K \alpha$ & Mo $K \alpha$ & Mo $K \alpha$ & Mo $K \alpha$ \\
\hline Unique Reflections & 238 & 235 & 222 & 212 & 220 & 214 & 219 & 218 & 219 \\
\hline $\mathrm{R}_{4 \sigma}(\%)$ & 3.87 & 4.35 & 3.42 & 4.11 & 4.07 & 3.69 & 5.03 & 3.80 & 4.07 \\
\hline $\mathrm{N}^{\circ}$ parameters & 21 & 21 & 21 & 21 & 21 & 21 & 21 & 21 & 21 \\
\hline \multicolumn{10}{|c|}{$\begin{array}{l}\text { Bulk modulus, } K_{\mathrm{T} 0}=124.4 \mathrm{GPa} \\
\text { First pressure derivative, } K^{\prime}=4.9\end{array}$} \\
\hline \multicolumn{10}{|c|}{$\mathrm{Fo}_{80} \mathrm{Fa}_{20}$} \\
\hline$P(\mathrm{GPa})$ & 0 & $1.06(5)$ & $1.69(5)$ & $3.00(5)$ & 3.71(5) & $5.78(5)$ & $7.66(5)$ & & \\
\hline$a(\AA)$ & $4.766(3)$ & $4.765(2)$ & $4.760(2)$ & $4.750(3)$ & $4.744(2)$ & $4.733(4)$ & $4.724(2)$ & & \\
\hline$b(\AA)$ & $10.251(7)$ & $10.213(5)$ & $10.188(5)$ & $10.151(6)$ & $10.134(6)$ & $10.066(8)$ & $10.027(5)$ & & \\
\hline$c(\AA)$ & $6.022(7)$ & $6.005(2)$ & $5.997(4)$ & $5.979(4)$ & $5.971(3)$ & $5.938(5)$ & $5.906(4)$ & & \\
\hline$V\left(\AA^{3}\right)$ & 294.2(4) & 292.2(2) & $290.8(3)$ & $288.3(3)$ & 287.1(3) & $282.9(4)$ & $279.8(3)$ & & \\
\hline S.G. & Pbnm & Pbnm & Pbnm & Pbnm & Pbnm & Pbnm & Pbnm & & \\
\hline Radiation & 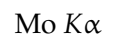 & Mo $K \alpha$ & Mo $K \alpha$ & Mo $K \alpha$ & Mo $K \alpha$ & Mo $K \alpha$ & Mo $K \alpha$ & & \\
\hline Unique Reflections & 277 & 256 & 251 & 249 & 248 & 251 & 239 & & \\
\hline $\mathrm{R}_{4 \sigma}(\%)$ & 6.08 & 4.05 & 3.95 & 3.97 & 4.55 & 5.51 & 4.35 & & \\
\hline $\mathrm{N}^{\circ}$ parameters & 21 & 21 & 21 & 21 & 21 & 21 & 21 & & \\
\hline \multicolumn{10}{|c|}{$\begin{array}{l}\text { Bulk modulus, } K_{\mathrm{T} 0}=124.7(3) \mathrm{GPa} \\
\text { First pressure derivative, } K^{\prime}=5.4(2)\end{array}$} \\
\hline \multicolumn{10}{|c|}{$\mathrm{Fo}_{62} \mathrm{Fa}_{38}$} \\
\hline$P$ (GPa) & 0 & $0.76(5)$ & $1.93(5)$ & $2.86(5)$ & 5.07(5) & $7.46(5)$ & $8.34(5)$ & & \\
\hline$a(\AA)$ & $4.797(2)$ & $4.796(2)$ & $4.785(3)$ & $4.776(2)$ & $4.761(2)$ & $4.745(2)$ & $4.741(2)$ & & \\
\hline$b(\AA)$ & $10.330(4)$ & $10.296(4)$ & $10.283(4)$ & $10.248(4)$ & $10.183(4)$ & $10.100(4)$ & $10.079(4)$ & & \\
\hline$c(\AA)$ & $6.041(2)$ & $6.040(1)$ & $6.019(1)$ & $6.008(1)$ & $5.981(1)$ & $5.949(1)$ & $5.939(1)$ & & \\
\hline$V\left(\AA^{3}\right)$ & 299.3(2) & $298.25(18)$ & $296.2(2)$ & $294.06(18)$ & $289.97(17)$ & $285.10(17)$ & $283.79(17)$ & & \\
\hline S.G. & Pbnm & Pbnm & Pbnm & Pbnm & Pbnm & Pbnm & Pbnm & & \\
\hline Radiation & 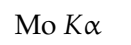 & $\operatorname{Mo} K \alpha$ & $\operatorname{Mo} K \alpha$ & 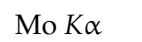 & Mo $K \alpha$ & Mo $K \alpha$ & Mo $K \alpha$ & & \\
\hline Unique Reflections & 207 & 206 & 205 & 177 & 195 & 190 & 189 & & \\
\hline $\mathrm{R}_{4 \sigma}(\%)$ & 6.84 & 5.95 & 5.59 & 8.23 & 7.28 & 4.41 & 5.25 & & \\
\hline $\mathrm{N}^{\circ}$ parameters & 21 & 21 & 21 & 21 & 21 & 21 & 21 & & \\
\hline \multicolumn{10}{|c|}{$\begin{array}{l}\text { Bulk modulus, } K_{\mathrm{T} 0}=126.6(4) \mathrm{GPa} \\
\text { First pressure derivative, } K^{\prime}=5.2(1)\end{array}$} \\
\hline
\end{tabular}

Note: Bulk moduli and first pressure derivatives from [18].

The evolution of the M2 and M1 polyhedral volumes (plotted as $V / V_{0}$ ) with pressure is shown in Figure 2. All samples displayed similar behaviour, where the M2 polyhedron compressed more than M1. Thus, the evolution of the M2 polyhedron volume is likely the main factor influencing the compression mechanism in olivine. 

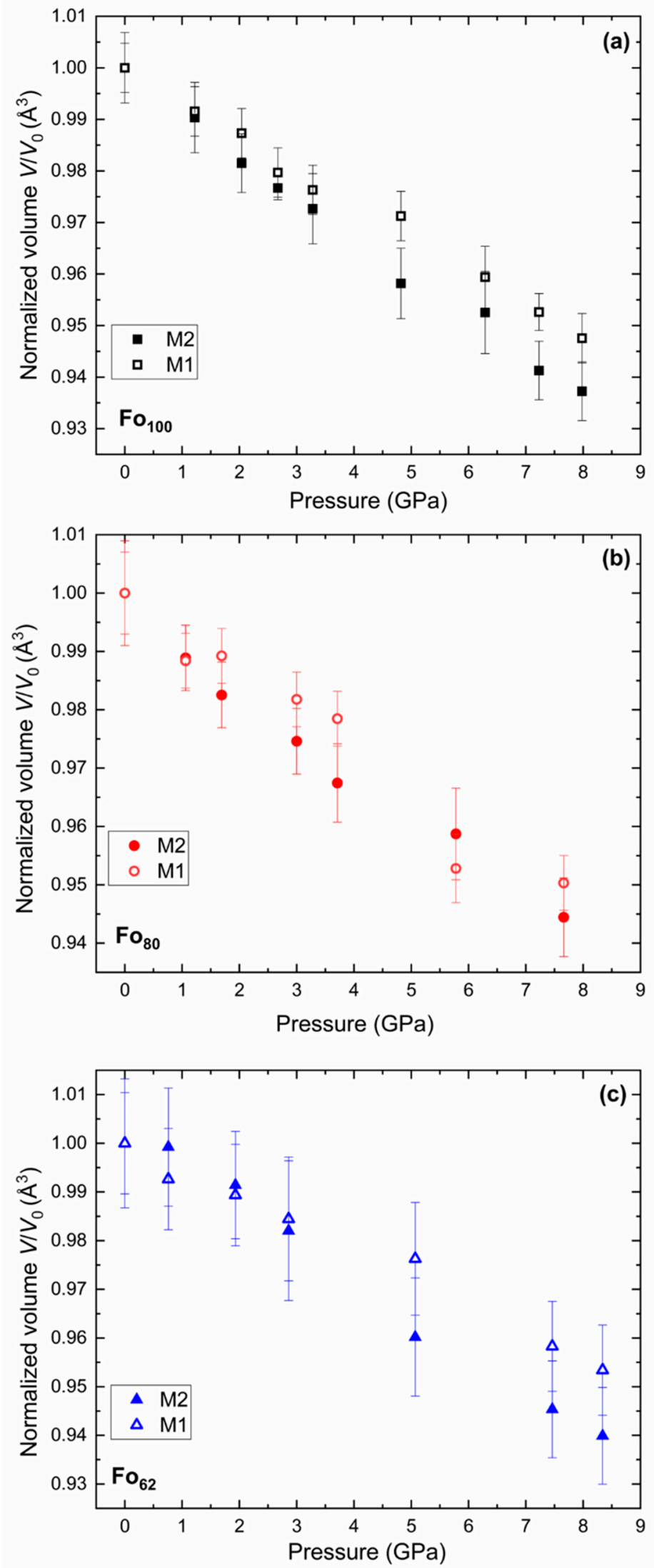

Figure 2. The evolution of normalized $V / V_{0}$ for $\mathrm{M} 2$ and $\mathrm{M} 1$ polyhedra: (a) $\mathrm{Fo}_{100}$; (b) $\mathrm{Fo}_{80}$; (c) $\mathrm{Fo}_{62}$. 
The polyhedral volume compressibility, expressed as $\beta=\left[V-V_{0} / V_{0}\right] / \Delta P$, can be used to compare the effect of composition (Fe content) on the compressional behaviour of olivine. Based on data reported in Table S1, the values obtained for M2 and M1 polyhedra, respectively, are:

$$
\begin{aligned}
& \mathrm{Fo}_{100}: \beta=-0.0079(5) \text { and }-0.0066(4) \mathrm{GPa}^{-1}, \\
& \mathrm{Fo}_{80}: \beta=-0.0073(5) \text { and }-0.0065(4) \mathrm{GPa}^{-1}, \\
& \mathrm{Fo}_{62}: \beta=-0.0072(5) \text { and }-0.0056(4) \mathrm{GPa}^{-1} \text {. }
\end{aligned}
$$

These values seem to indicate that $\mathrm{Fo}_{62}$ is the stiffest structure and $\mathrm{Fo}_{100}$ is the most compressible. However, when considering the associated uncertainties, the observed differences of $\beta$ between $\mathrm{Fo}_{100}$ and $\mathrm{Fo}_{62}$ are negligible over the large compositional range. The polyhedral volume of the unique tetrahedral site does not present any significant variations over the pressure range investigated for all compositions, indicating that the Si tetrahedron is a rigid unit, as commonly observed in silicate minerals (e.g., [20]).

The volume distortions of the $\mathrm{M} 2$ and $\mathrm{M} 1$ polyhedra were calculated using the IVTON software [32] as $\left[V_{\mathrm{i}}-V_{\mathrm{p}}\right] / V_{\mathrm{i}}$, where $V_{\mathrm{i}}$ is the volume of the ideal polyhedron and $V_{\mathrm{p}}$ the volume of the coordination polyhedron. These data are reported in Table S1. In general, the M1 polyhedron in olivine is smaller and more distorted than the M2 [5,6]. However, at room pressure, the M2 and M1 octahedra showed an almost identical distortion for $\mathrm{Fo}_{100}$ and $\mathrm{Fo}_{80}$. In contrast, both the M2 and M1 octahedra in $\mathrm{Fo}_{62}$ were more distorted (between $18 \%$ and $25 \%$ ) when compared to $\mathrm{Fo}_{100}$ and $\mathrm{Fo}_{80}$. This behaviour may explain the compressibility change toward higher bulk moduli in more Fe-rich compositions. Instead, the Si tetrahedron was again the most regular, regardless of the composition considered.

The M2-O and M1-O bond lengths are reported in Table S1 and their evolution as a function of pressure is displayed in Figures 3 and 4.

As expected, from the behaviour of the polyhedral volumes, the $\mathrm{M} 2-\mathrm{O}$ average values exhibited the largest variation in pressure, with the T-O average distances essentially unchanged over the entire pressure range. This observation further confirms that the M2 crystallographic site, with its bonding configuration, controls the compressibility of olivine. However, it is not clear whether a different compression trend was observed over the compositional range studied in this work. In fact, by normalizing the single bond length compressions (using a simple linear calculation, where the difference between the initial and final bond lengths values are normalized over the pressure range investigated, providing the compression in $\AA / \mathrm{GPa}$ ), the $\mathrm{M}-\mathrm{O}$ differences obtained for $\mathrm{Fo}_{100}$ to $\mathrm{Fo}_{62}$ were modest, if not negligible (Table 2).

Table 2. Bond length compressions for M2 and M1 polyhedra (in $\AA / G P a)$.

\begin{tabular}{ccccc}
\hline & $\mathbf{F o}_{\mathbf{1 0 0}}$ & $\mathbf{F o}_{\mathbf{8 0}}$ & $\mathbf{F o}_{\mathbf{6 2}}$ & $\mathbf{F o}_{\mathbf{0}}$ \\
\hline M2-O1 & 0.008 & 0.007 & 0.009 & 0.009 \\
M2-O2 & 0.005 & 0.006 & 0.006 & 0.007 \\
M2-O31 × 2 & 0.013 & 0.012 & 0.010 & 0.008 \\
M2-O3s × 2 & 0.011 & 0.007 & 0.009 & 0.012 \\
Mean compression rate (Å/GPa) & $\mathbf{0 . 0 0 6}$ & $\mathbf{0 . 0 0 5}$ & $\mathbf{0 . 0 0 6}$ & $\mathbf{0 . 0 0 6}$ \\
M1-O1 × 2 & 0.012 & 0.012 & 0.007 & 0.012 \\
M1-O2 × 2 & 0.008 & 0.005 & 0.006 & 0.004 \\
Mean compression rate (Å/GPa) & 0.010 & 0.011 & 0.013 & 0.008 \\
\hline
\end{tabular}

Values were calculated from the data reported in Table S1 and from the CIF files deposited by Zhang et al. [20] for $\mathrm{Fo}_{0}$ (between 3.9 and $12.3 \mathrm{GPa}$, see text). All data are normalized to ensure a reliable comparison. Uncertainties are $\leq 0.002 \AA / G P a$ for M2-O lengths and $\leq 0.001 \AA / G P a$ for M1-O lengths. 

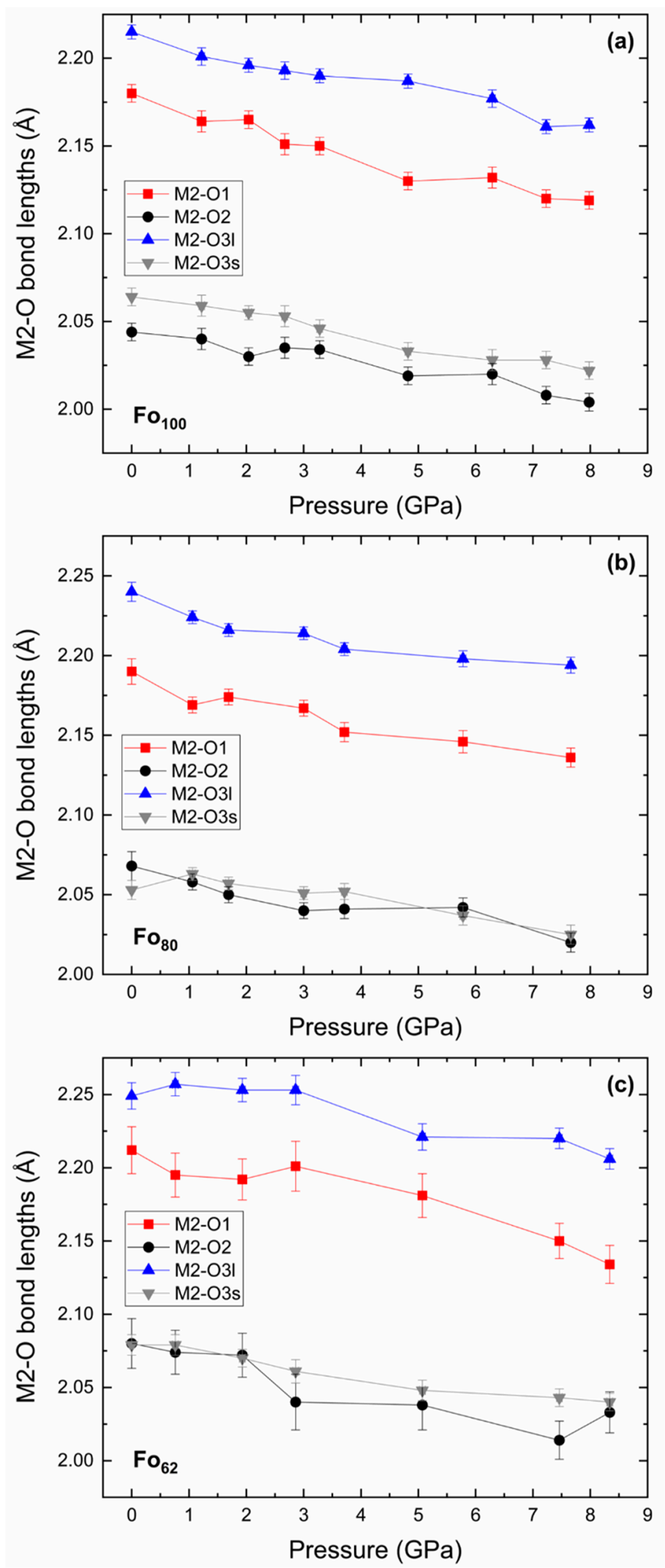

Figure 3. $\mathrm{M} 2-\mathrm{O}$ bond distance versus pressure for samples (a) $\mathrm{Fo}_{100}$, (b) $\mathrm{Fo}_{80}$, and (c) $\mathrm{Fo}_{62}$. Symbols: red squares, M2O1; black circle, M2O2; blue upward triangle, M2-O31; grey downward triangle, M2-O3s. Lines connect points over the investigated pressure range for a particular bond distance and only serve as guides. 

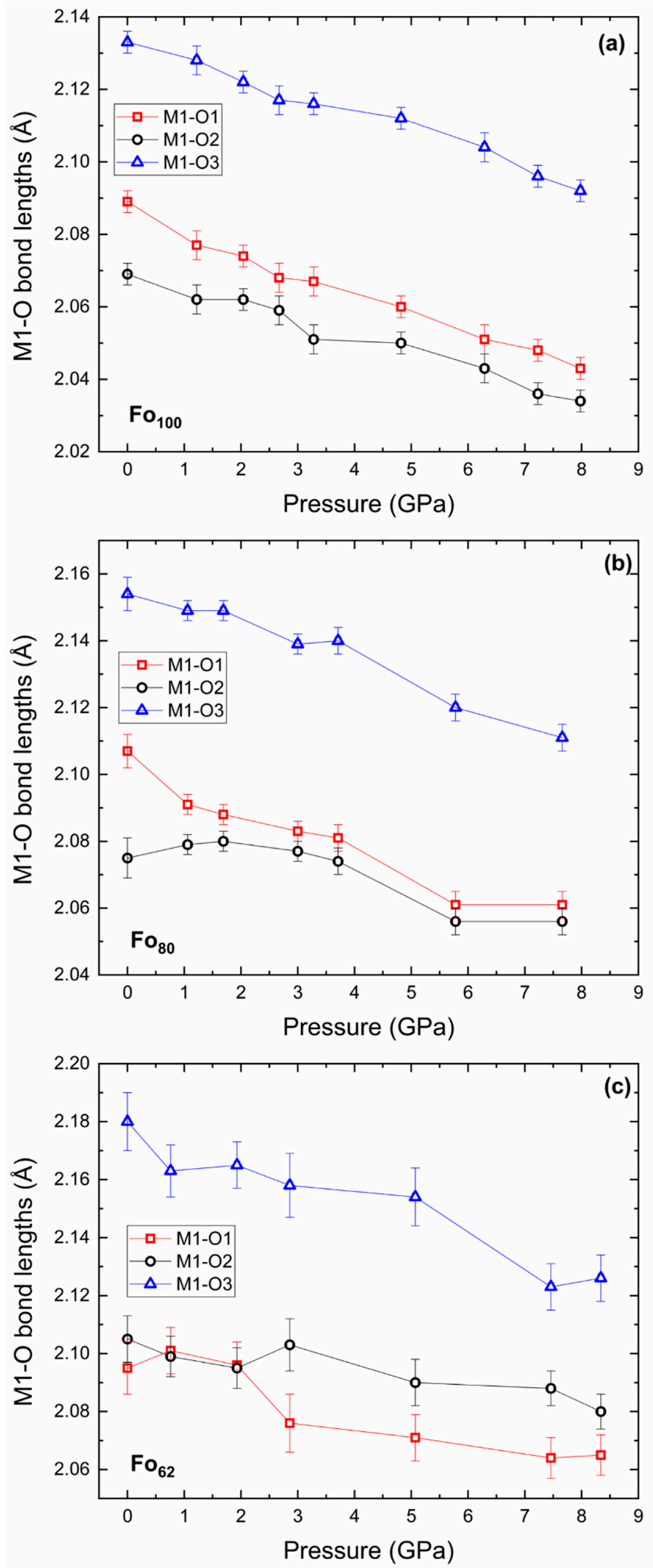

Figure 4. M1-O bond distance versus pressure for samples (a) $\mathrm{Fo}_{100}$, (b) $\mathrm{Fo}_{80}$, and (c) $\mathrm{Fo}_{62}$. Symbols: red squares, M1O1; black circles, M1O2; blue upward triangles, M1-O3. Lines connect points over the investigated pressure range for a particular bond distance and only serve as guides. 


\section{Discussion}

Before discussing the high-pressure structural variation as a function of composition, it is important to note that no significant bulk modulus variations were observed in the compositional range investigated by Nestola et al. [18], that is, between $\mathrm{Fo}_{92}$ and $\mathrm{Fo}_{62}$. However, the data by Nestola et al. [18] showed a possible tendency to develop a stiffer structure for $\mathrm{Fo}_{62}$, with slightly higher linear moduli along the crystallographic $a$ and $c$ axes, while no differences were observed along the $b$ axis. Combining the small variations along these axes resulted in a slightly higher bulk modulus for $\mathrm{Fo}_{62}$, closer to $127 \mathrm{GPa}$ [18].

The results presented here for Mg-rich olivines can be interpreted with the most recent data of Bejina et al. [22] and Speziale et al. [16] on Fe-rich olivines. These data indicate that increasing the Fe content along the forsterite-fayalite join causes a slight but significant increase in the bulk modulus of olivine. The total increase from $\mathrm{Fo}_{100}$ to $\mathrm{Fo}_{0}$ could be quantified as approximately $9 \%$. However, the increment with Fe content of $K_{\mathrm{T} 0}$ was non-linear: from $\mathrm{Fo}_{100}$ to approximately $\mathrm{Fo}_{60}$, the bulk modulus was almost constant with values between 124 and $126 \mathrm{GPa}$, whereas from $\mathrm{Fo}_{60}$ to $\mathrm{Fo}_{18}$ a large variation from $\sim 126$ to $136 \mathrm{GPa}$ was observed. No significant variations were detected between $\mathrm{Fo}_{18}$ and $\mathrm{Fo}_{0}$. Nevertheless, $K^{\prime}$ remained nearly constant over the entire compositional $\mathrm{Fo}-\mathrm{Fa}$ join, with a value close to 5 . This value was calculated based on the data of Nestola et al. [18] and Speziale et al. [16], as all other studies in the literature fixed the $K^{\prime}$ to 4 . As mentioned above, it appears that two plateaus for the Mg-rich and the Fe-rich portions of the join are present [22] (see their Figure 8). In order to explain these bulk modulus differences, it would be useful to compare structural data for olivine within this compositional range, but unfortunately the only recent data on single crystals are those presented in this study and in Zhang et al. [20] on fayalite. The pioneering work of Hazen [7] and Kudoh and Takeuchi [9] were not considered in this study, as their data were collected when high-pressure protocols were at their initial stages, three to four decades ago. Since the bulk modulus does not show any significant variations between $\mathrm{Fo}_{20}$ and $\mathrm{Fo}_{0}$, the structural data for $\mathrm{Fo}_{100}, \mathrm{Fo}_{80}$, $\mathrm{Fo}_{62}$ and $\mathrm{Fo}_{0}$ can be compared. Zhang et al. [20] investigated $\mathrm{Fo}_{0}$ up to $31 \mathrm{GPa}$; however, only data between 3.7 and 12.3 GPa were considered, which correspond to a pressure range of $8.4 \mathrm{GPa}$ (similar to what was investigated in this study). A first direct comparison with fayalite can be done relative to the compressions of the M1-O and M2-O bond lengths. As observed for Mg-rich compositions, $\mathrm{M} 2-\mathrm{O}$ lengths were the most compressible also in fayalite. Thus, the main deformation mechanism in olivine is driven by the M2 bonding configuration. However, the mean compression rate for the $\mathrm{M} 2-\mathrm{O}$ bond lengths was identical between the two end-members, with values of $0.006,0.005,0.006$, and $0.006 \AA / \mathrm{GPa}$ for $\mathrm{Fo}_{100}, \mathrm{Fo}_{80}, \mathrm{Fo}_{62}$, and $\mathrm{Fo}_{0}$, respectively (values obtained summing the single compression rates reported in Table 2 and divided by the number of bond distances). The same calculation performed for the M1-O bond lengths provides compression rates of $0.005,0.005,0.004$, and $0.004 \AA / \mathrm{GPa}$ for $\mathrm{Fo}_{100}, \mathrm{Fo}_{80}, \mathrm{Fo}_{62}$, and $\mathrm{Fo}_{0}$, respectively. The compression rate for $\mathrm{M} 2-\mathrm{O}$ and $\mathrm{M} 1-\mathrm{O}$ bond lengths controls the relative polyhedral volumes, resulting in a less-compressible M1 polyhedron from $\mathrm{Fo}_{100}$ to $\mathrm{Fo}_{0}$, causing a slight increase in the bulk modulus with increasing Fe content. These small structural variations can also explain the almost constant first pressure derivative of the bulk modulus along the forsterite-fayalite join, indicating a very similar structural compression motif.

Supplementary Materials: The following are available online at http://www.mdpi.com/2075-163X/9/12/790/s1, Table S1: Bond lengths and polyhedral data for the olivine crystals studied here.

Author Contributions: Conceptualization, M.G.P., F.N., and D.N.; methodology, F.N., J.R.S., D.P., G.D.G., and L.S.; writing—original draft preparation, M.G.P., F.N., and D.N.; writing-review and editing, M.G.P., F.N., D.N., J.R.S., D.P., G.D.G., M.A., L.S. All authors have read and agreed to the published version of the manuscript.

Funding: M.G.P. received funding from the European Union's Horizon 2020 research and innovation programme under the Marie Skłodowska-Curie grant agreement No 796755. D.N. and M.A. are supported by a European Research Council (ERC) grant under the European Union's Horizon 2020 research and innovation programme (grant agreement No 714936 for the project TRUE DEPTHS to M.A.). 
Acknowledgments: We thank the Guest Editor Claudia Romano for handling the manuscript and two anonymous reviewers for their comments that improved the manuscript.

Conflicts of Interest: The authors declare no conflicts of interest. The funders had no role in the design of the study; in the collection, analyses, or interpretation of data; in the writing of the manuscript, or in the decision to publish the results.

\section{References}

1. Bass, J.D.; Parise, J.B. Deep-Earth and recent developments in mineral physics. Element 2008, 4, 157-163. [CrossRef]

2. Ringwood, A.E. Composition of the core and implications for origin of earth. Geochem. J. 1977, 11, 111-135. [CrossRef]

3. Agee, C.B. Phase transformations and seismic structure in the upper mantle and transition zone. In Ultrahigh-Pressure Mineralogy: Physics and Chemistry of the Earth's Deep Interior; Hemley, R.J., Ed.; Mineralogical Society of America: Chantilly, VA, USA, 1998; Volume 37, pp. 165-203.

4. Frost, D.J. $\mathrm{Fe}^{2+}-\mathrm{Mg}$ partitioning between garnet, magnesiowustite, and $(\mathrm{Mg}, \mathrm{Fe})_{2} \mathrm{SiO}_{4}$ phases of the transition zone. Am. Mineral. 2003, 88, 387-397. [CrossRef]

5. Bragg, W.L.; Brown, G.B. Die struktur des olivins. Z. Krist.-Cryst. Mater. 1926, 63, 538-556. [CrossRef]

6. Smyth, J.R.; Jacobsen, S.D.; Hazen, R.M. Comparative crystal chemistry of orthosilicate minerals. In High-Temperature and High-Pressure Crystal Chemistry; Hazen, R.M., Downs, R.T., Eds.; Mineralogical Society of America: Chantilly, VA, USA, 2000; Volume 41, pp. 187-209.

7. Hazen, R.M. Effects of temperature and pressure on the crystal structure of ferromagnesian olivine. Am. Mineral. 1977, 62, 286-295.

8. Suzuki, I.; Anderson, O.L.; Sumino, Y. Elastic properties of a single crystal forsterite $\mathrm{Mg}_{2} \mathrm{SiO}_{4}$, up to $1200 \mathrm{~K}$. Phys. Chem. Miner. 1983, 10, 38-46. [CrossRef]

9. Kudoh, Y.; Takeuchi, Y. The crystal structure of forsterite $\mathrm{Mg}_{2} \mathrm{SiO}_{4}$ under high pressure up to $149 \mathrm{~kb}$. Z. Krist.-Cryst. Mater. 1985, 171, 291-302.

10. Graham, E.K.; Schwab, J.A.; Sopkin, S.M.; Takei, H. The pressure and temperature dependence of the elastic properties of single crystal fayalite $\mathrm{Fe}_{2} \mathrm{SiO}_{4}$. Phys. Chem. Miner. 1988, 16, 186-198. [CrossRef]

11. Webb, S.L. The elasticity of the upper mantle orthosilicates olivine and garnet to 3 GPa. Phys. Chem. Miner. 1989, 16, 684-692. [CrossRef]

12. Andrault, D.; Bouhifd, M.A.; Itié, J.P.; Richet, P. Compression and amorphization of $(\mathrm{Mg}, \mathrm{Fe})_{2} \mathrm{SiO}_{4}$ olivines: An X-ray diffraction study up to 70 GPa. Phys. Chem. Miner. 1995, 22, 99-107. [CrossRef]

13. Downs, R.T.; Zha, C.S.; Duffy, T.S.; Finger, L.W. The equation of state of forsterite to $17.2 \mathrm{GPa}$ and effects of pressure media. Am. Mineral. 1996, 81, 51-55. [CrossRef]

14. Zha, C.S.; Duffy, T.S.; Downs, R.T.; Mao, H.K.; Hemley, R.J. Sound velocity and elasticity of single-crystal forsterite to 16 GPa. J. Geophys. Res. 1996, 101, 17535-17545. [CrossRef]

15. Zha, C.S.; Duffy, T.S.; Downs, R.T.; Mao, H.K.; Hemley, R.J. Brillouin scattering and X-ray diffraction of San Carlos olivine: Direct pressure determination to 32 GPa. Earth Planet. Sci. Lett. 1998, 159, 25-33. [CrossRef]

16. Speziale, S.; Duffy, T.S.; Angel, R.J. Single-crystal elasticity of fayalite to 12 GPa. J. Geophys. Res. 2004, 109, B12202. [CrossRef]

17. Liu, W.; Kung, J.; Li, B. Elasticity of San Carlos olivine to 8 GPa and 1073 K. Geophys. Res. Lett. 2005, 32, L16301. [CrossRef]

18. Nestola, F.; Pasqual, D.; Smyth, J.R.; Novella, D.; Secco, L.; Manghnani, M.H.; Dal Negro, A.D. New accurate elastic parameters for the forsterite-fayalite solid solution. Am. Mineral. 2011, 96, 1742-1747. [CrossRef]

19. Finkelstein, G.J.; Dera, P.K.; Jahn, S.; Oganov, A.R.; Holl, C.M.; Meng, Y.; Duffy, T.S. Phase transitions and equation of state of forsterite to $90 \mathrm{GPa}$ from single-crystal X-ray diffraction and molecular modelling. Am. Mineral. 2014, 99, 35-43. [CrossRef]

20. Zhang, J.S.; Hu, Y.; Shelton, H.; Kung, J.; Dera, P. Single-crystal X-ray diffraction study of $\mathrm{Fe}_{2} \mathrm{SiO}_{4}$ fayalite up to 31 GPa. Phys. Chem. Miner. 2017, 44, 171-179. [CrossRef]

21. Angel, R.J.; Alvaro, M.; Nestola, F. 40 years of mineral elasticity: A critical review and a new parameterisation of equations of state for mantle olivines and diamond inclusions. Phys. Chem. Miner. 2018, 45, 95-113. [CrossRef] 
22. Béjina, F.; Bystricky, M.; Tercé, N.; Whitaker, M.L.; Chen, H. Bulk modulus of Fe-rich olivines corrected for non-hydrostaticity. C. R. Geosci. 2019, 351, 86-94. [CrossRef]

23. Smyth, J.R.; Frost, D.J.; Nestola, F.; Holl, C.M.; Bromiley, G. Olivine hydration in the deep upper mantle: Effects of temperature and silica activity. Geophys. Res. Lett. 2006, 33, L15301. [CrossRef]

24. Princivalle, F.; Secco, L. Crystal structure refinement of 13 olivines in the forsterite-fayalite series from volcanic rocks and ultramafic nodules. Tschermaks Mineral. Petrogr. Mitt. 1985, 34, 105-115. [CrossRef]

25. Angel, R.J.; Bujak, M.; Zhao, J.; Gatta, G.D.; Jacobsen, S.D. Effective hydrostatic limits of pressure media for high-pressure crystallographic studies. J. Appl. Crystallogr. 2007, 40, 26-32. [CrossRef]

26. Klotz, S.; Chervin, J.-C.; Munsch, P.; Le Marchand, G. Hydrostatic limits of 11 pressure transmitting media. J. Phys. D Appl. Phys. 2009, 42, 075413. [CrossRef]

27. Mao, H.K.; Xu, J.; Bell, P.M. Calibration of the ruby pressure gauge to $800 \mathrm{kbar}$ under quasi-hydrostatic conditions. J. Geophys. Res. 1986, 91, 4673-4676. [CrossRef]

28. Angel, R.J. Absorption corrections for diamond-anvil cell implemented in the software package Absorb 6.0. J. Appl. Crystallogr. 2004, 37, 486-492. [CrossRef]

29. STOE \& Cie. X-SHAPE, Version 1.06; Stoe \& Cie: Darmstadt, Germany, 1999.

30. Sheldrick, G.M. SHELXS97 and SHELXL97. Program for Crystal Structure Solution and Refinement; University of Göttingen: Göttingen, Germany, 1997.

31. Fujino, K.; Sasaki, S.; Takéuchi, Y.; Sadanaga, R. X-ray determination of electron distributions in forsterite, fayalite and tephroite. Acta Crystallogr. 1981, B37, 513-518. [CrossRef]

32. Balic-Zunic, T.; Vickovic, I. IVTON: A program for the calculation of geometrical aspects of crystal structures and some crystal chemical applications. J. Appl. Crystallogr. 1996, 29, 305-306. [CrossRef]

(C) 2019 by the authors. Licensee MDPI, Basel, Switzerland. This article is an open access article distributed under the terms and conditions of the Creative Commons Attribution (CC BY) license (http://creativecommons.org/licenses/by/4.0/). 